\title{
Effect of Various Types of Intermittent Fasting (IF) on Weight Loss and Improvement of Diabetic Parameters in Human
}

\author{
Karolina Nowosad $^{1} \cdot$ Monika Sujka $^{1}$ (D) \\ Accepted: 23 March 2021 / Published online: 7 April 2021 \\ (C) The Author(s) 2021
}

\begin{abstract}
Purpose of Review A number of recent studies have suggested that intermittent fasting is as effective as traditional calorie restriction (CR) for weight loss and for cardioprotection. However, it is still unclear whether IF improves diabetes risk indicators as does CR. This review provides an overview of various patterns of intermittent fasting and shows the effect of intermittent fasting on human anthropometric such as excess body weight and biochemical parameters for example high glucose and fasting insulin, which are risk factors for diabetes.

Recent Findings There is a growing body of evidence pointing to the benefits of intermittent fasting for glucose and insulin homeostasis, but this should be confirmed by further studies in population groups with (or at high risk) type II diabetes and insulin resistance. Long-term studies are also needed that could reveal potential negative health effects that some studies report.

Summary Eleven studies in overweight/obese adult people that included changes in weight, body composition, and diabetic parameters (fasting glucose, fasting insulin, HbAlc concentration, and HOMA-IR index) were published between 2012 and 2020. Seven studies concerning the effects of alternate day fasting (ADF) on weight loss and diabetic parameters were analyzed. All of them have shown the effects of ADF on weight loss and slight improvement in diabetic parameters. For time-restricted feeding (TRF), a significant improvement in the HOMA-IR index was observed in 2 studies. One study saw an increase in fasting glucose. An analysis of 2 studies using a complete alternate day fasting (CADF) was performed. One study showed decrease in fasting glucose and insulin, and in one a decrease in glycosylated hemoglobin (HbAlc) was observed.

Conclusion Different types of intermittent fasting reduce body weight and reduce diabetes parameters such as fasting glucose, fasting insulin, HOMA-IR index, and glycated hemoglobin (HbA1c).
\end{abstract}

Keywords Anthropometric parameters $\cdot$ Intermittent fasting $\cdot$ Obesity $\cdot$ Fasting glucose $\cdot$ Fasting insulin $\cdot$ HOMA-IR

\section{Introduction}

The number of overweight or obese people is constantly increasing. Obesity is one of the factors in the development of insulin resistance and diabetes. A weight loss of $1 \mathrm{~kg}$ reduces the risk of diabetes by as much as $16 \%$ [1]. To reduce weight and improve body composition (fat, muscle, and water contents), it is necessary to introduce physical activity and a diet with a negative calorie balance. There are a number of weight loss diets that allow to lose body fat and reduce the risk of

This article is part of the Topical Collection on Diabetes and Obesity

Monika Sujka

monika.sujka@up.lublin.pl

1 Department of Analysis and Evaluation of Food Quality, University of Life Sciences in Lublin, Skromna 8, 20-704 Lublin, Poland diseases associated with excessive body weight [1]. One of the alternative methods of reducing kilocalories (kcal) intake is intermittent fasting [2]. Intermittent fasting (IF) is a broad term encompassing various programs that manipulate meal time, using short-term fast to improve body composition and overall health [3]. This method consists in refraining from eating for a specific period of time, e.g., $16 \mathrm{~h}$, and then eating meals in socalled feeding window, which lasts, e.g., $8 \mathrm{~h}$. IF can be modified - periods of fasting or "eating window" were lengthened or shortened [2]. An example of such a modification is alternating eating 1 day and then fasting the next day. On the day of fasting, one meal (most often consumed at lunch) is usually eaten, which does not exceed $25 \%$ of the daily caloric demand [4]. Another example of IF modification is the introduction of 1 or 2 days fasting per week. During the fast, one can completely eliminate food or reduce calories to a minimum [5] (Tables 1 and 2). 
Table 1 Types of intermittent fasting [6], with permission

Complete alternate day fasting

Alternate day fasting

Time-restricted feeding

Religious fasting
Alternating fasting days (without consuming high energy food and drinks) with eating days (eating and drinking ad libitum)

It allows consumption from 20 to $25 \%$ of energy demand on scheduled fasting days. This scheme forms the basis of the popular 5:2 diet, which is associated with severe energy restriction for 2 uninterrupted days a week and eating ad libitum for the remaining 5 days.

Eating meals with a certain energy value during the "food window," which lasts several hours. The most common modification is eating for $8 \mathrm{~h}$, followed by fasting for the next $16 \mathrm{~h}$. The hours of fasting and eating can be shortened and extended.

A wide range of fasts is undertaken for religious or spiritual purposes
Glucose and lipid homeostasis can be improved by a slight weight loss, which, according to current dietary recommendations, is most often achieved through moderate continuous (daily) energy reduction (CER). Regardless of weight loss, metabolic regulation of glucose and lipids can also be affected by other dietary manipulations, including changes in meal time [7] as well as sudden changes in energy status, such as fasting [8]. Most studies on IF have considered whether IF could be a potential strategy to lose weight and improve diabetic parameters in human [9]. Several modifications of IF have gained popularity as they offer impressive health benefits. However, it is unlikely that all IF schemes lead to the same physiological changes because of their different fasting and feeding patterns [3].

A number of recent studies have suggested that IF is also effective, as is traditional calorie restriction (CR) for weight loss and for improve diabetic parameters. However, it is still unclear whether IF improves diabetes risk indicators as does $\mathrm{CR}$. This review provides an overview of various patterns of IF and shows the effect of IF on human anthropometric and biochemical parameters (Table 3). The review focuses mainly on human research in recent years. The main aim of this article is to present the effects of IF on weight loss, fasting glucose, fasting insulin, and insulin sensitivity in overweight and obese adults.

\section{Search Strategy and Selection Criteria}

\section{Eligibility Criteria}

This review seeks to answer the research question "How do different types of intermittent fasting affect diabetes parameters in overweight or obese people?" The inclusion and exclusion criteria and search strategy were developed according to the PICO framework.

\section{Inclusion Criteria}

- Population: obese or overweight people with a BMI above 25.0 or people with normal body weight with type II diabetes, aged $>18$ years, women and men.

- Problem: excess body weight, abnormal fasting glucose or insulin levels, HOMA-IR, or glycosylated hemoglobin.

- Intervention: use of different types of intermittent fasting (TRF, ADF, CADF).

- Result: changes in body composition (weight loss, fat, and lean mass loss), change in biochemical parameters (fasting glucose, fasting insulin, HOMA-IR index, glycated hemoglobin).

- Type of study: randomized controlled trials, cross-over, pilot studies, case studies, published between 2005 and 2020, written in English.

Table 2 Sample schedule of food intake during various modifications of IF [3], with permission

\begin{tabular}{|c|c|c|c|c|c|c|c|}
\hline Modification of IF & Day 1 & Day 2 & Day 3 & Day 4 & Day 5 & Day 6 & Day 7 \\
\hline $\begin{array}{l}\text { Alternate day fasting } \\
\text { (ADF) }\end{array}$ & Ad libitum & $25 \% \mathrm{kcal}$ & Ad libitum & $25 \% \mathrm{kcal}$ & Ad libitum & $25 \% \mathrm{kcal}$ & Ad libitum \\
\hline $\begin{array}{l}\text { Time-restricted feeding } \\
\text { (TRF) }\end{array}$ & $\begin{array}{r}16-20 \mathrm{~h} \text { of fasting, } \\
4-8 \mathrm{~h} \text { of feeding }\end{array}$ & $\begin{array}{l}16-20 \mathrm{~h} \text { of } \\
\text { fasting, } \\
4-8 \mathrm{~h} \text { of } \\
\text { feeding }\end{array}$ & $\begin{array}{l}16-20 \mathrm{~h} \text { of } \\
\text { fasting, } \\
4-8 \mathrm{~h} \text { of } \\
\text { feeding }\end{array}$ & $\begin{array}{r}16-20 \mathrm{~h} \text { of fasting, } \\
4-8 \mathrm{~h} \text { of feeding }\end{array}$ & $\begin{array}{c}16-20 \mathrm{~h} \text { of } \\
\text { fasting, } \\
4-8 \mathrm{~h} \text { of } \\
\text { feeding }\end{array}$ & $\begin{array}{r}16-20 \mathrm{~h} \text { of fasting, } \\
4-8 \mathrm{~h} \text { of feeding }\end{array}$ & $\begin{array}{r}16-20 \mathrm{~h} \text { of fasting, } \\
4-8 \mathrm{~h} \text { of feeding }\end{array}$ \\
\hline $\begin{array}{l}\text { Complete alternate day } \\
\text { fasting (CADF) }\end{array}$ & Ad libitum & Ad libitum & Ad libitum & Ad libitum/24-h fast & Ad libitum & Ad libitum & 24-h fast \\
\hline
\end{tabular}




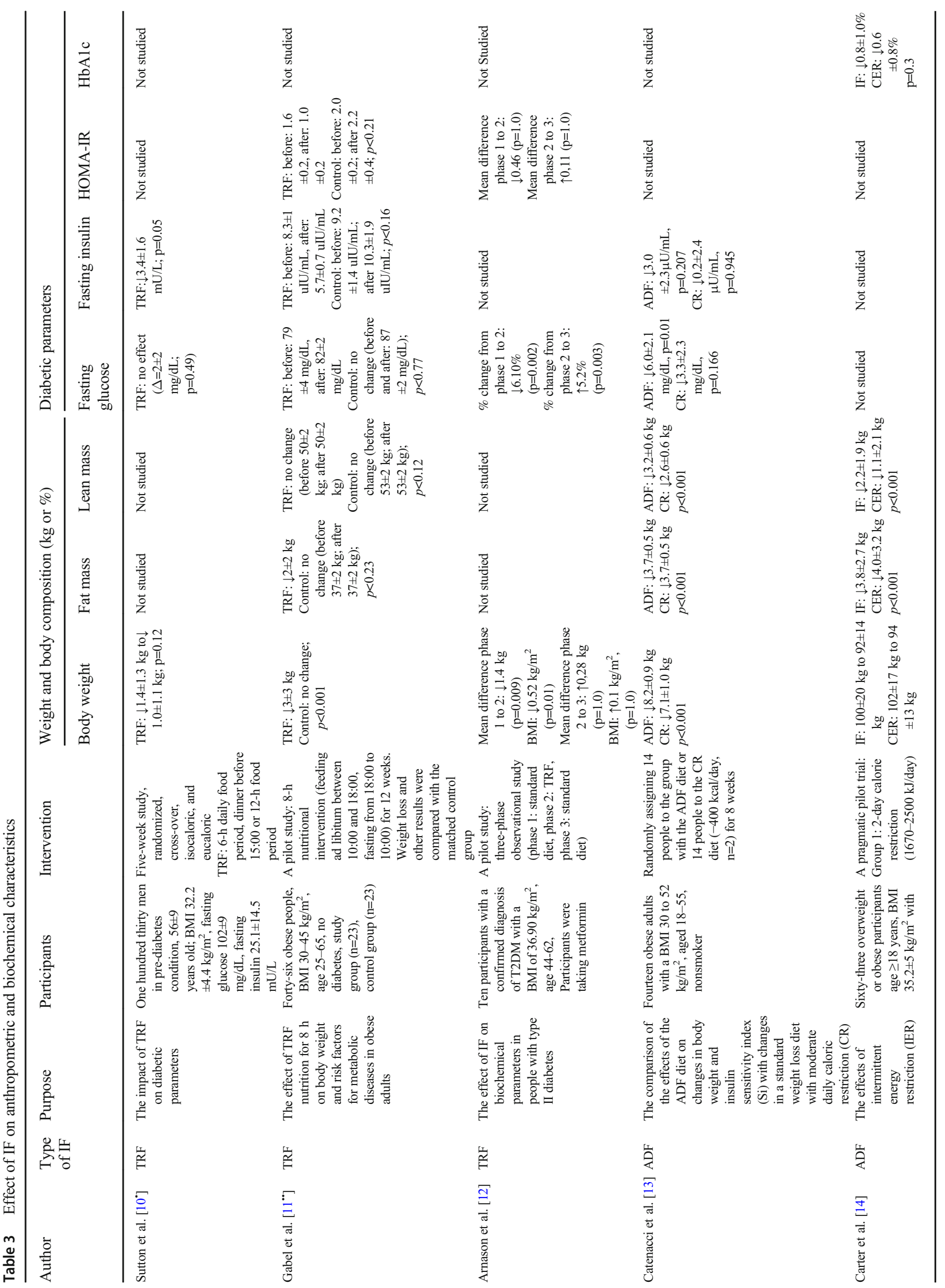




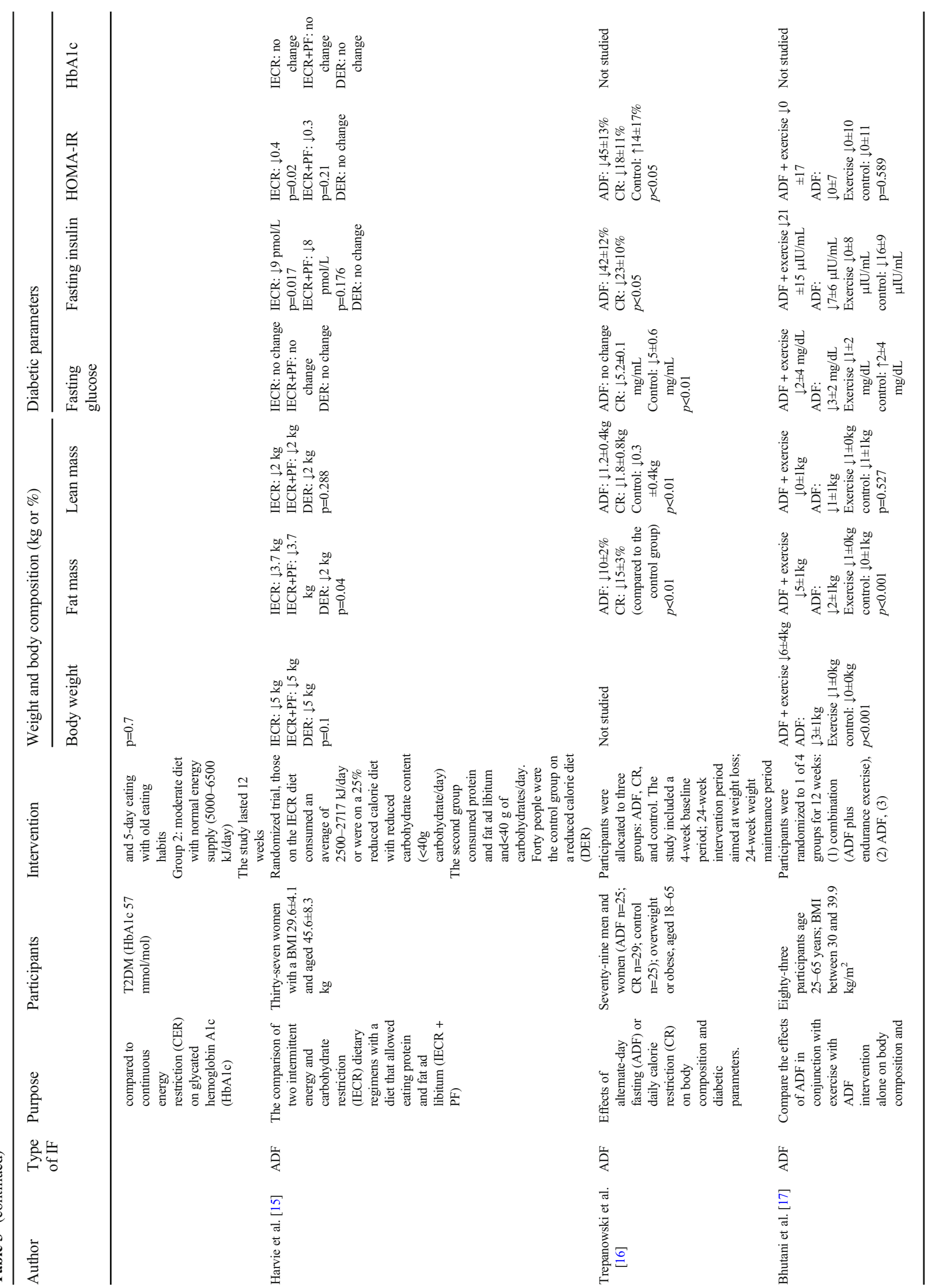




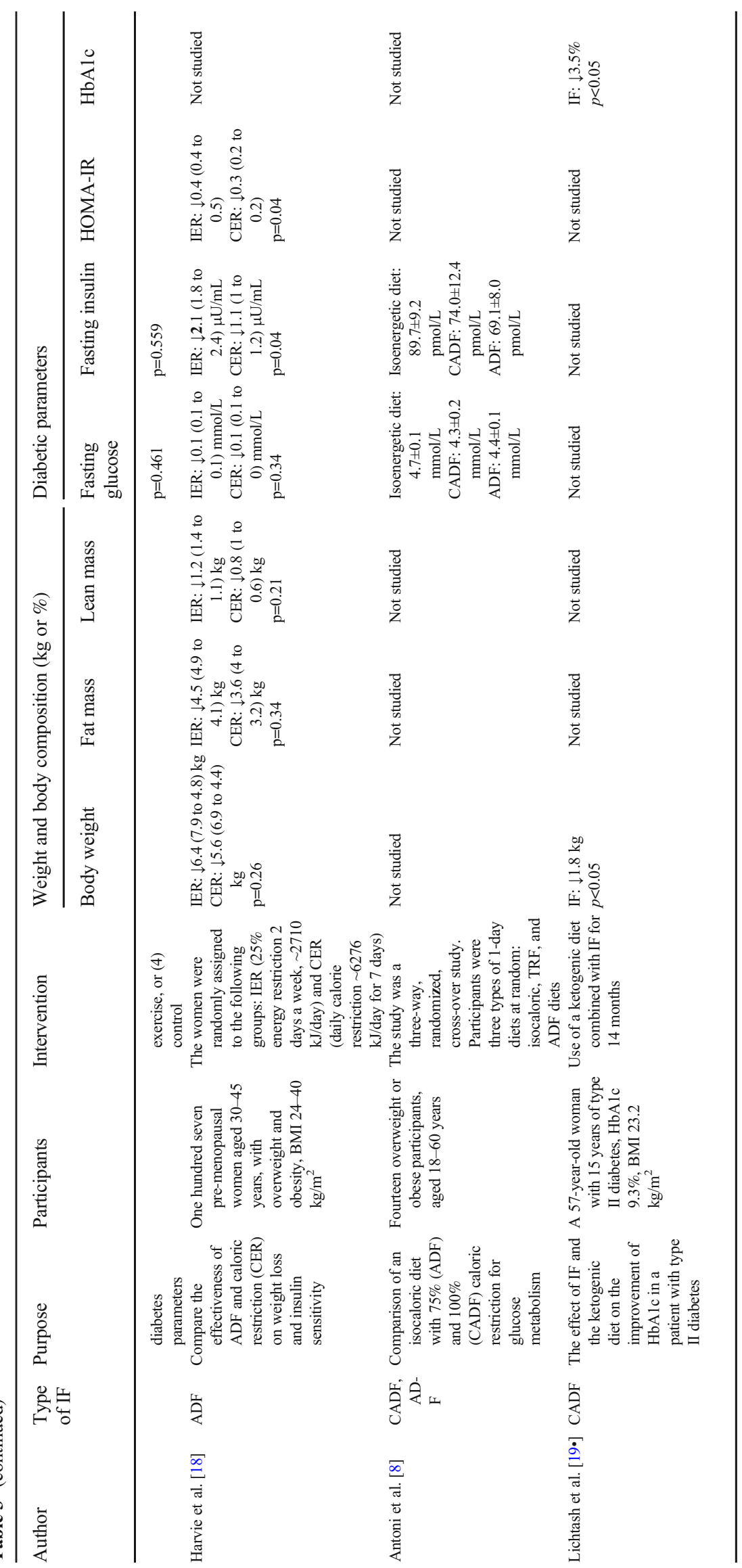




\section{Exclusion Criteria}

- Population: children aged $<18$ years, people with normal body weight without type II diabetes.

- Problem: no changes in biochemical parameters, alternating several types of intermittent fasting.

- Intervention: using of intermittent fasting for a short time, e.g., 1 day.

- Result: does not directly measure the effects of an intervention.

- Type of research: review articles, opinion articles, editorials, letters, news reports, policy or legislative literature; animal research; published before 2005 or after 2020, written in a language other than English.

Two databases, PubMed and Scopus, were searched in September 2020 to find research and review articles concerning an impact of intermittent fasting on human health. The following phrases were searched: "post IF," "intermittent fasting," "IF human." Then, in order to narrow the search, the following keywords were used: "impact of IF," "influence IF on human health," "IF diabetic parameters," "IF glucose," "intermittent fasting glucose," "IF body mass," "intermittent fasting body mass," "IF lose weight," "intermittent fasting insulin." Then we searched for articles describing the impact of a specific type of periodic fasting (ADF, TRF, CADF) on human anthropometric and biochemical parameters: "ADF human health," "ADF glucose," "ADF body mass," "ADF weight," "ADF insulin," "ADF HOMA-IR," "ADF HbA1c," "TRF human health," "TRF glucose," "TRF body mass," "TRF weight," "TRF insulin," "TRF HOMA-IR," "TRF HbA1c" and "CADF human health," "CADF glucose," "CADF body mass," "CADF weight," "CADF insulin," "CADF HOMA-IR," "CADF HbA1c." The articles were examined based on the title and summary. When the abstract was not available or the information was insufficient to decide on inclusion in the review article, the full text was read. Then the following data was extracted: size and details of the research or the control group, duration, nutrition strategy, and measure of results.

\section{Results and Discussion}

Eleven studies were published between 2005 and 2020. We analyzed three studies describing the effects of TRF on weight loss and diabetics parameters. All studies have shown the effects of TRF on weight loss, but in one study, this effect is not statistically significant. One study additionally investigated the effects of TRF on fat loss. TRF also reduced fasting glucose (in 1 case) and fasting insulin (in 2 cases). In two studies, time-restricted feeding had an effect on reducing HOMA-IR. The effect of TRF on HbAlc levels has not been studied in any of the articles. For ADF, significant weight loss was observed in 5 studies and it was caused by a loss of body fat. Four studies showed reduction in fasting glucose and one study in HbAlc. In six studies, ADF had an effect on fasting insulin levels and in four studies on HOMA-IR index. In 2 studies in which post-CADF was used, a decrease in fasting glucose and fasting insulin was observed. This had the effect of reducing the fasting glucose and insulin (which was tested in one of the studies). HbAlc decreased in 1 case. Detailed information about the research can be found in the following paragraphs.

Sutton et al. [10"] conducted a 5-week RCT study among 130 men with pre-diabetes. The participants were assigned to the TRF eating schedule, which consisted of a 6-h eating window and eating the last meal at 3 p.m., and to the control group, which had an extended eating window to $12 \mathrm{~h}$. Men started the eating window at $8.00 / 8.30$. Study participants ate only meals prepared by staff and received the amount of calories needed to maintain their weight. After 5 weeks of TRF, participants had an improvement in insulin sensitivity relative to baseline. The use of TRF did not affect the energy expenditure among the respondents. Probably the insignificant difference in body weight between the control group and the test group was caused by the reduction of glycogen levels and the accompanying water loss.

Gabel et al. [11“] also introduced an 8-h eating window for 23 obese people. In this pilot study, participants ate meals ad libitum in the eating window for 12 weeks. Another 23 people (randomly selected) constituted the control group, whose members were asked to maintain their weight throughout the study and not to change their eating habits or physical activity. The participants were tested for body composition, glycemic, and lipid parameters. After 12 weeks of using the TRF dietary regimen, weight loss and improvement in blood pressure were observed. There were no statistically significant differences between the groups in the case of fat mass and lean mass. TRF did not significantly improve fasting glucose but caused a decrease of fasting insulin levels and thereby improved HOMA-IR.

Arnason et al. [12] investigated the short-term biochemical effects of intermittent fasting (TRF) in 10 adults with type 2 diabetes (T2DM) taking metformin. The pilot study consisted of three phases (baseline -2 weeks, intervention -2 weeks, observation -2 weeks), followed by biochemical and anthropometric measurements, and the level of participants' activity. Patients had the choice of using intermittent fasting in the morning, afternoon, or evening; however, all participants preferred to start their meals in the afternoon. Short-term intermittent fasting resulted in significant weight loss $(-1.395 \mathrm{~kg})$, BMI (-0.517), and at-target morning glucose (SMBG). SMBG (self-monitoring of blood glucose) is an important component of self-management in diabetes and enables it people with diabetes make the daily decisions necessary to 
achieve and maintain proper control glycemia [12]. Increasing the duration of fasting improved fasting glucose values. Neither insulin resistance (HOMA-IR) nor markers of inflammation (C-reactive protein) did not normalize during intermittent fasting. During phase 3 (standard diet), there was a slight increase in weight and BMI of the study participants, which also resulted in an increase in fasting glucose (by 5.2\%). Intermittent fasting reduced post-prandial hyperglycemia (39.4\% vs $47.4 \%$ of the baseline value). The weight loss was due to a reduced caloric intake (18\% from baseline), which resulted in improved participants' diabetes parameters.

The randomized pilot study by Catenacci et al. [13] concerned the effect of ADF on body weight, body composition, and the insulin sensitivity index ( $\mathrm{Si}$ ). A total 26 obese subjects participated in the study, with 14 subjects assigned to an intermittent fasting diet, while the remaining 12 subjects were the controls on a standard low-calorie diet. The study lasted 8 weeks. For ADF, participants achieved a $376 \mathrm{kcal}$ greater deficit than participants in the control group, but this significantly affects weight, body composition, and insulin sensitivity index.

Carter et al. [14] made similar conclusions. Their study involved 63 overweight and obese people who were assigned ADF and a standard reduction diet with a caloric value of 5000-6500 $\mathrm{kJ} /$ day. ADF consisted of a 2-day caloric restriction of 1670 $2500 \mathrm{~kJ} /$ day and a 5-day ad libitum diet for 12 weeks. There were no significant differences between the two groups in terms of body weight, body composition, and improvement in $\mathrm{HbAlc}$.

Improvement in insulin sensitivity was observed in randomized trial by Harvie et al. [15]. Two dietary regimens were tested in their study: intermittent fasting with energy and carbohydrate restriction (IECR) and intermittent fasting, which allowed ad libitum protein and fat (IECR + PF), and the results were compared to a daily calorie-restricted diet. The intermittent fasting regimen included a 25\% calorie reduction 2 days a week. The study involved 115 overweight women who reported breast cancer in a family history. A reduction in the fasting indicators of insulin resistance (fasting glucose, fasting insulin, HOMA-IR index) was observed in both groups. A reduction in body fat percentage was observed for both groups using intermittent fasting (IECR: average - $3.7 \mathrm{~kg}$; IECR + PF: average - 3.7 $\mathrm{kg}$; DER: average $-2.0 \mathrm{~kg}$ ).

In the RCT study by Trepanowski et al. [16], participants were randomized to an ADF diet, a caloric restriction (CR) group, and a control group. Both ADF and CR significantly improved participants' anthropometric parameters. In the group on $\mathrm{ADF}$, no changes in fasting glucose levels were observed, while improvements in fasting insulin and the associated HOMA-IR index were observed.

Bhutani et al. [17] investigated the effect of ADF in combination with exercise on changes in body composition and biochemical parameters in the randomized study. For this purpose, obese people were assigned to 4 groups: ADF with exercise, $\mathrm{ADF}$, exercise, and a control group. Body weight decreased in the $\mathrm{ADF}$ with exercise, $\mathrm{ADF}$, and exercise only groups by $6 \pm 4$ $\mathrm{kg}, 3 \pm 1 \mathrm{~kg}$, and $1 \pm 0 \mathrm{~kg}$, respectively, at $\mathrm{p}<0.005$. ADF and exercise also improved diabetes parameters (fasting insulin levels and HOMA-IR index). Weight loss was associated with an improvement in cell sensitivity to insulin.

In the randomized study by Harvie et al. [18], the effects of intermittent fasting (ADF) were compared with caloric restriction in terms of weight loss and improvement in insulin sensitivity. The study involved 107 women with BMI $>30 \mathrm{~kg} / \mathrm{m}^{2}$. Both $\mathrm{ADF}$ and caloric restriction were shown to decrease body weight by $-6.4(-7.9$ to -4.8$) \mathrm{kg}$ and -5.6 (-6.9 to $-4.4) \mathrm{kg}$, respectively. The improvement in fasting insulin levels was modest in both group, but was greater in the ADF group. Both intermittent fasting and daily caloric reduction have been shown to be an effective method of losing weight and improving diabetic parameters.

In the randomized, cross-over study by Antoni et al. [8], participants randomly followed three 1-day diets: an isocaloric diet, $75 \%$ calorie restriction (ADF), and $100 \%$ calorie restriction (CADF). The study compared the effects of an isocaloric diet and intermittent fasting on glucose metabolism. The study shows the significant effect of CADF and ADF in reducing fasting glucose and insulin levels. The lowest fasting glucose and insulin levels were obtained with CADF, and the highest with an isocaloric diet.

The effect of intermittent fasting in combination with a ketogenic diet on HbAlc in a healthy body weight woman with type II diabetes was investigated in a case study. The ketogenic diet consisted of the following macronutrient composition: 5\% carbohydrates, $15 \%$ protein, and $80 \%$ fat. The patient had not previously seen any improvement in glycaemia following the standard dietary approach (low glycemic index diet with calorie restriction). Intermittent fasting was introduced for $24 \mathrm{~h}$ three times a week, then $42 \mathrm{~h}$ three times a week, then $42 \mathrm{~h}$ twice a week, and $16 \mathrm{~h}$ a week. After 8 months, the IF was reduced to $16 \mathrm{~h}$ a day, with $24 \mathrm{~h}$ three times a month, and metformin was reintroduced. After 14 months, HbAlc reached 5.8\%, and the body mass index slightly changed [19॰]. When selecting the study, the time of eating meals was taken into account in accordance with the idea of intermittent fasting, because the ketogenic diet determines the type of food that should be eaten (it shows what nutrients should consist of a meal), but does not contain indications regarding the time of meals (i.e., when the meal should be eaten).

\section{Conclusions}

Pre-clinical and clinical studies have shown that intermittent fasting has a wide range of benefits for many diseases, including obesity, diabetes, and insulin resistance. The results of human studies, in which various indicators of health are measured at the beginning and after periods of IF of 2-6 months or longer, suggest that IF may protect against diabetes and obesity. 
Recent studies have produced promising results that strongly support further clinical trials in patients with chronic age-related disorders and obesity. An important clinical and scientific question is whether adopting a regular, intermittent fasting regimen is a viable and sustainable strategy that can be used in health promotion. In addition, adequate clinical trials are needed to see if intermittent fasting can supplement or replace energy restriction, and if so, can facilitate long-term improvement in metabolism and weight control. This review suggests that intermittent fasting regimens may be a promising approach to losing weight and improving blood chemistry in people who can safely tolerate interruptions or eat very little during certain hours of the day, night, or days of the week.

\section{Declarations}

Conflict of Interest All authors declare that they have no conflict of interest.

Human and Animal Rights and Informed Consent This article does not contain any studies with human or animal subjects performed by the authors.

Open Access This article is licensed under a Creative Commons Attribution 4.0 International License, which permits use, sharing, adaptation, distribution and reproduction in any medium or format, as long as you give appropriate credit to the original author(s) and the source, provide a link to the Creative Commons licence, and indicate if changes were made. The images or other third party material in this article are included in the article's Creative Commons licence, unless indicated otherwise in a credit line to the material. If material is not included in the article's Creative Commons licence and your intended use is not permitted by statutory regulation or exceeds the permitted use, you will need to obtain permission directly from the copyright holder. To view a copy of this licence, visit http://creativecommons.org/licenses/by/4.0/.

\section{References}

Papers of particular interest, published recently, have been highlighted as:

- Of importance

•- Of major importance

1. Donnelly JE, Blair SN, Jakicic JM. Appropriate physical activity intervention strategies for weightloss and prevention of weight regain for adults. Med Sci Sports Exerc. 2009;41:459-71. https://doi. org/10.1249/MSS.0b013e3181949333.

2. Brown JE, Mosley M, Aldred S. Intermittent fasting: a dietary intervention for pre-vention of diabetes and cardiovascular disease? Br J Diabetes Vasc Dis. 2013;13:68-72. https://doi.org/10.1177/ 1474651413486496.

3. Tinsley GM, La Bounty PM. Effects of intermittent fasting on body composition and clinical health markers in humans. Nutr Rev. 2015;73(10):661-74. https://doi.org/10.1093/nutrit/nuv041.
4. Varady KA, Bhutani S, Klempel MC. Alternate day fasting for weight loss innormal weight and overweight subjects: a randomized controlled trial. Nutr J. 2013;12:146. https://doi.org/10.1186/14752891-12-146.

5. Hussin NM, Shahar S, Teng NIMF. Efficacy of fasting and calorie restriction (FCR) on mood and depression among ageing men. J Nutr Health Aging. 2013;17:674-80. https://doi.org/10.1016/j. physbeh.2011.07.007.

6. Patterson RE, Laughlin GA, LaCroix AZ, Hartman SJ, Natarajan L, Senger CM, et al. Intermittent fasting and human metabolic health. J Acad Nutr Diet. 2015;115(8):1203-12. https://doi.org/10.1016/j. jand.2015.02.018.

7. Potter G, Cade JE, Grant P. Nutrition and the circadian system. Br J Nutr. 2016;16:434 42. https://doi.org/10.1017/S0007114516002117.

8. Antoni R, Johnston K, Collins A. Investigation into the acute effects of total and partial energy restriction on postprandial metabolism among overweight/obese participants. Br J Nutr. 2016;115:951-9. https://doi.org/10.1017/S0007114515005346.

9. Mattson MP, Longo VD, Harvie M. Impact of intermittent fasting on health and disease processes. Ageing Res Rev. 2017;39:46-58. https://doi.org/10.1016/j.arr.2016.10.005.

10. Sutton EF, et al.. Early time-restricted feeding improves insulin sensitivity, blood pressure, and oxidative stress even without weight loss in men with prediabetes. Cell Metab 2018;27(6): 1212-1221. DOI: 10.1016/j.cmet.2018.04.010. This research article assessed the effect of intermittent fasting on isnulin sensitivity in men at risk for type II diabetes regardless of weight loss. TRF has been shown to improve insulin sensitivity and reduce the desire to eat in the evening, which may promote weight loss. This article showed for the first time that the effects of IF are not solely due to weight loss.

11.• Gabel K, et al. Efects of 8-hour time restricted feeding on body weight and metabolic disease risk factors in obese adults: a pilot study. J Nutr Health Aging 2018;4(4):345-353. doi: 10.3233/NHA-170036. This study investigated the effects of 8-h time-restricted feeding on body weight and metabolic disease risk factors in obese adults.

12. Arnason TG, Bowen MW, Mansell KD. Effects of intermittent fasting on health markers in those with type 2 diabetes: a pilot study. World J. Diabetes. 2017;8(4):154-64. https://doi.org/10. 4239/wjd.v8.i4.154.

13. Catenacci VA, Pan Z, Ostendorf D, Brannon S, Gozansky WS, Mattson MP, et al. A randomized pilot study comparing zero-calorie alternate-day fasting to daily caloric restriction in adults with obesity. Obes. 2016;24(9):1874-83. https://doi.org/10.1002/oby.21581.

14. Carter S, Clifton PM, Keogh JB. The effects of intermittent compared to continuous energy restriction on glycaemic control in type 2 diabetes; a pragmatic pilot trial. Diabetes Res Clin. 2016;122: 106-12. https://doi.org/10.1016/j.diabres.2016.10.010.

15. Harvie M, Wright C, Pegington M, McMullan D, Mitchell E, Martin B, et al. The effect of intermittent energy and carbohydrate restriction v. daily energy restriction on weight loss and metabolic disease risk markers in overweight women. Br J Nutr. 2013;110(8): 1534 47. https://doi.org/10.1017/S0007114513000792.

16. Trepanowski JF, Kroeger CM, Barnosky A, Klempel M, Bhutani S, Hoddy KK, et al. Effects of alternate-day fasting or daily calorie restriction on body composition, fat distribution, and circulating adipokines: secondary analysis of a randomized controlled trial. Clin Nutr. 2018;37(6):1871-8. https://doi.org/10.1016/j.clnu.2017.11.018.

17. Bhutani S, Klempel MC, Kroeger CM, Trepanowski JF, Varady KA. Alternate day fasting and endurance exercise combine to reduce body weight and favorably alter plasma lipids in obese humans. Obesity. 2013;21(7):1370-9. https://doi.org/10.1002/oby.20353. 
18. Harvie MN, Pegington M, Mattson MP, Frystyk J, Dillon B, Evans $\mathrm{G}$, et al. The effects of intermittent or continuous energy restriction on weight loss and metabolic disease risk markers: a randomized trial in young overweight women. Int J Obes. 2011;35(5):714-27. https://doi.org/10.1038/ijo.2010.171.

19. Lichtash C, et al. Therapeutic use of intermittent fasting and ketogenic diet as an alternative treatment for type 2 diabetes in a normal weight woman: a 14-month case study. BMJ Case Rep 2020;13(7).
DOI: $10.1136 /$ bcr-2019-234223. This article demonstrates the effective use of intermittent fasting (IF) and the ketogenic diet (KD) in a weight-neutral type 2 diabetic patient who has not achieved glycemic control on a low IG diet.

Publisher's Note Springer Nature remains neutral with regard to jurisdictional claims in published maps and institutional affiliations. 